\title{
Addressing students' emotional needs during the COVID-19 pandemic: a perspective on text versus video feedback in online environments
}

\author{
Regina Kaplan-Rakowski ${ }^{1}$ D
}

Accepted: 10 November 2020 / Published online: 19 November 2020

(c) Association for Educational Communications and Technology 2020

\begin{abstract}
This paper reflects on the findings of Borup et al. (Educ Technol Res Dev 63:161-184, 2015) regarding the efficiency and affect of text and video feedback in the context of the rapid shift to online education due to the COVID-19 pandemic. Based on reports of diminished mental wellness, increased depression, and anxiety among learners and instructors, this paper offers ideas on how to apply the findings from Borup et al. (Educ Technol Res Dev 63:161-184, 2015) from a combination of practice, research, design, and inclusion perspectives to ensure emotional support, mental wellness, and social presence during times of crisis, even at the expense of efficiency of instruction.
\end{abstract}

Keywords Emotional learning · Wellness · Text feedback · Video feedback · COVID-19 . Online and blended learning $\cdot$ Online environments

In this paper, I extend the findings of Borup, West, and Thomas in their 2015 Educational Technology Research and Development paper entitled "The Impact of Text Versus Video Communication on Instructor Feedback in Blended Courses," by setting their topic of text and video feedback in the context of the rapid shift of education to the online format brought on by the outbreak of the COVID-19 pandemic. I offer practice, research, design, and inclusion perspectives that are relevant during and following the pandemic. These perspectives center on the importance of prioritizing wellness over efficiency in times of crisis.

As evidenced by instructors' and students' surveys, Borup et al. (2015) found that both students and instructors perceived text and video feedback as equally valuable with regard to quality and delivery. Quality was evaluated by how consistent, useful, and specific the feedback was. Delivery referred to how supportive and respectful the feedback was. Qualitative analyses illustrated that text feedback was more efficient and more organized than video feedback. Meanwhile, according to end-of-term interviews with students, video feedback was "more conversational, supportive, and fully developed"

Regina Kaplan-Rakowski

Regina.Kaplanrakowski@unt.edu

1 Department of Learning Technologies, College of Information, University of North Texas, $3940 \mathrm{~N}$.

Elm Street, G159, Denton, TX 76207, USA 
(p. 179) than text feedback. Further, video feedback provided valuable nonverbal cues, offering more praising elements and fostering relationship building. Regardless, "both students and instructors valued the efficiency of text over the more affective benefits of video" (p. 161).

In other words, the Borup et al. (2015) findings showed that the emotional aspect of feedback was less valuable than efficiency, but they may apply differently during times of crisis, such as the COVID-19 pandemic. While teaching and learning efficiency should always be a concern (Merrill 2002), the pandemic and the rapid shift to online learning have increased focus on the importance of emotional learning, mental health, and wellness issues (Ferdig et al. 2020; Hall et al. 2020; Hamilton et al. 2020; Hartshorne et al. 2020; Roman 2020).

The pandemic outbreak impacted the entire world. Literature about the global situation during the pandemic documents an increased state of depression and anxiety among people (Rajkumar 2020), including diminished mental wellness among students and faculty (Hartshorne et al. 2020). Therefore, instructors may need to reevaluate or even switch priorities. Instead of strictly striving for efficiency, they should place greater stress on providing increased emotional support during times of crisis.

One of the ways to prioritize emotional support in distance learning is through the implementation of synchronous and asynchronous video for communication and feedback (Borup et al. 2012; Kilgore 2018). While synchronous videoconferencing has its values (e.g., immediate feedback, spontaneity), it is less convenient due to scheduling constraints and the risk of "Zoom hangovers" (Schulman 2020). Asynchronous video may allow for more flexibility in timing and longer reflection on the assignments. Asynchronous video and video-mediated feedback enhance social presence (Borup et al. 2012, 2014). As reported by Lowenthal et al. (2020), asynchronous video proved useful during the rapid transfer from face-to-face format to online learning as a result of the COVID-19 outbreak, by increasing engagement and sustaining connections between socially isolated faculty and students. In the context of feedback, Lowenthal et al. (2020) promoted screencasting as a particularly useful way to provide feedback on projects involving visuals.

While Borup et al. (2015) had a valuable impact on research and practices in educational technology, the study was further limited in that it was set in a blended, instead of a purely online, learning format. Students had a chance to meet their instructors at least one time. Therefore, much-needed social presence may have already been initiated and established. Such a scenario may not have the same applicability with strictly online delivery, as experienced during a social distancing protocol.

Even after the COVID-19 pandemic is over, its repercussions likely will linger for years. Medical researchers confirmed that the psychological consequences of COVID-19 resemble the symptoms of post-traumatic stress disorder (Masiero et al. 2020; Tang et al. 2020), which means that prioritizing the wellness of students, even at the cost of less efficiency of instruction, may be a desirable modification that educators should address, at least during the times of social isolation and mental stress that accompany the pandemic. Meanwhile, instructors should keep in mind that video feedback is not panacea for any learning scenario. Instead, the type of feedback should be selected with respect to situational principles (Reigeluth and Carr-Chellman 2009). For example, while video feedback may be relevant for an assignment in a computer graphics course, it may not be pertinent for feedback on a multiple-choice quiz.

This article addresses students' emotional needs during the pandemic by offering practice, research, design, and inclusion perspectives on text versus video feedback in online environments. The key message is that educators should shift to a more affective approach 
during times of crisis, and one way to do this is by implementing video for communication and feedback.

Formative evaluation and studies testing the best approaches to address mental needs for students and educators during times of social isolation are necessary. Approaches to consider include not only creating social presence and providing emotional feedback using videos or Zoom Cafés (Johnson and Merrick 2020) but also setting up a learning environment that encourages mind and body balance, such as by the implementation of wellness techniques (e.g., meditation, yoga, exercise) in daily instruction. These approaches could have implications that benefit students and instructors as well as other individuals bound to home-office settings.

\section{Compliance with ethical standards}

Conflict of interest The author declares that she has no conflict of interest.

Human participants or animals This submission did not involve human participants or animals.

\section{References}

Borup, J., West, R. E., \& Graham, C. R. (2012). Improving online social presence through asynchronous video. The Internet and Higher Education, 15(3), 195-203.

Borup, J., West, R. E., Thomas, R. A., \& Graham, C. R. (2014). Examining the impact of video feedback on instructor social presence in blended courses. International Review of Research in Open and Distributed Learning, 15(3), 232-256.

Borup, J., West, R. E., \& Thomas, R. (2015). The impact of text versus video communication on instructor feedback in blended courses. Education Technology Research and Development, 63, 161-184.

Ferdig, R. E., Baumgartner, E., Hartshorne, R., Kaplan-Rakowski, R., \& Mouza, C. (Eds). (2020). Teaching, technology, and teacher education during the COVID-19 pandemic: Stories from the field. Association for the Advancement of Computing in Education (AACE). Retrieved from https://www.learntechl ib.org/p/216903/.

Hall, J., Roman, C., Jovel-Arias, C., \& Young, C. (2020). Pre-service teachers examine digital equity amidst schools' COVID-19 responses. Journal of Technology and Teacher Education, 28(2), 435-442.

Hamilton, L. S., Kaufman, J. H., \& Diliberti, M. (2020). Teaching and leading through a pandemic: Key findings from the American educator panels spring 2020 COVID-19 surveys. Creative Commons Attribution 4.0 International Public License, 2020.

Hartshorne, R., Baumgartner, E., Kaplan-Rakowski, R., Mouza, C., \& Ferdig, R. E. (2020). Special issue editorial: Preservice and inservice professional development during the COVID-19 pandemic. Journal of Technology and Teacher Education, 28(2), 137-147.

Johnson, C., \& Merrick, B. (2020). Enabling music students' well-being through regular Zoom cohort chats during the COVID-19 crises. In R. E. Ferdig, E. Baumgartner, R. Hartshorne, R. Kaplan-Rakowski, \& C. Mouza (Eds.), Teaching, technology, and teacher education during the COVID-19 pandemic: Stories from the field (pp. 261-264). Waynesvile: Association for the Advancement of Computing in Education (AACE).

Kilgore, W. (2018). Humanizing online teaching and learning. Dallas, TX: Pressbooks.

Lowenthal, P., Borup, J., West, R., \& Archambault, L. (2020). Thinking beyond Zoom: Using asynchronous video to maintain connection and engagement during the COVID-19 pandemic. Journal of Technology and Teacher Education, 28(2), 383-391.

Masiero, M., Mazzocco, K., Harnois, C., Cropley, M., \& Pravettoni, G. (2020). From individual to social trauma: sources of everyday trauma in Italy, the US and UK during the COVID-19 pandemic. Journal of Trauma \& Dissociation. https://doi.org/10.1080/15299732.2020.1787296.

Merrill, M. D. (2002). First principles of instruction. Educational Technology Research and Development, 50(3), 43-59. 
Rajkumar, R. P. (2020). COVID-19 and mental health: A review of the existing literature. Asian Journal of Psychiatry, 52, 102066.

Reigeluth, C. M., \& Carr-Chellman, A. A. (Eds.). (2009). Instructional-design theories and models: Building a common knowledge base. New York: Routledge.

Roman, T. (2020). Supporting the mental health of preservice teachers in COVID-19 through traumainformed educational practices and adaptive formative assessment tools. Journal of Technology and Teacher Education, 28(2), 473-481.

Schulman, C. (2020, April 9). I used to shut my windows to New York's noise. Now I long for a honking horn. Washington Post. Retrieved from https://www.washingtonpost.com/outlook/2020/04/09/newyork-silent-coronavirus/.

Tang, W., Hu, T., Hu, B., Jin, C., Wang, G., Xie, C., et al. (2020). Prevalence and correlates of PTSD and depressive symptoms one month after the outbreak of the COVID-19 epidemic in a sample of homequarantined Chinese university students. Journal of Affective Disorders, 274, 1-7.

Publisher's Note Springer Nature remains neutral with regard to jurisdictional claims in published maps and institutional affiliations.

Regina Kaplan-Rakowski received her doctorate in Instructional Technology and Design from Southern Illinois University, Carbondale. She is currently a Lecturer and the Director of the Master of Science Program in Learning Technologies at the University of North Texas. Her main research focus is on learning and teaching using immersive technologies (e.g., virtual reality, augmented reality). Her background and passion for foreign language pedagogy and instructional technology inspired her to pursue research in technologyenhanced language learning. 